\title{
ORIGINAL ARTICLE ELECTIVE CARDIOVERSION: INDICATIONS, SUCCESS AND COMPLICATIONS. FIVE YEAR EXPERIENCE IN A TERTIARY CARE HOSPITAL IN PAKISTAN
}

\author{
Intisar Ahmed ${ }^{1}$, Hunaina Shahab ${ }^{1}$, Bilal Ahmed ${ }^{1}$, Pirbhat Shams ${ }^{1}$, Aamir Hameed Khan ${ }^{1}$ \\ ${ }^{1}$ Aga Khan University Karachi, Pakistan
}

\begin{abstract}
Objectives: This study aimed to determine the indications, success rate of elective cardioversion and its manifest complications.

Methodology: It is a retrospective study involving 53 patients. We reviewed the hospital records files for the demographic data including age, gender, as well as indication of cardioversion, duration of arrhythmia and date of cardioversion along with complications.

Results: Out of 53 patients, $58.5 \%$ (31) were males with a mean age of $48.17 \pm 18.43$ years. Arrhythmia related symptoms (palpitations and fatigue) were the indication for cardioversion in $44 \%$ (23) of the subjects. Our data showed that $98.1 \%$ (52) were cardioverted to sinus rhythm successfully with a median energy of 100 joules. Out of those who underwent successful cardioversion, $92.5 \%$ (49) were followed up till 1 year after the cardioversion. At six week follow up, all the patients were found in sinus rhythm. At 6 months follow up, 94.2\% (49) remained in sinus rhythm, while at 1 year follow up, 73\% (38) of the patients remained in sinus rhythm. All patients were anticoagulated for at least four weeks after cardioversion. None of the patients required pacemaker and none of them developed stroke after cardioversion.

Conclusion: Electrical cardioversion for atrial fibrillation and flutter is a low risk procedure in our population and it has a high success rate and relatively low complications.

Keywords: Electrical, Cardioversion. Complications, Pakistan

Citation: Ahmed I, Shahab H, Ahmed B, Shams P, Khan AH. Elective Cardioversion: Indications, Success and Complications. Five Year Experience in a Tertiary Care Hospital in Pakistan. Pak Heart J. 2021;54(03):219-223. DOI: https://doi.org/10.47144/phj.v54i3.2163
\end{abstract}

\section{INTRODUCTION}

Atrial flutter (AFL) and atrial fibrillation (AF) are independently associated with thromboembolic complications including stroke. ${ }^{1}$ These arrhythmias are also associated with tachycardia induced cardiomyopathy (TIC) as well as heart failure. ${ }^{2-4}$ The risk is further amplified when individuals experience other predisposing conditions such as hypertension, diabetes, smoking, valvular heart diseases, myocardial infarction and many other conditions. ${ }^{5}$ In addition to these complications, the quality of life is also affected. ${ }^{6,7}$ Treatment of AF currently consists of anticoagulation for the prevention of stroke and systemic embolism and strategies to control patients' symptoms with either rate or rhythm control. ${ }^{8}$ The 'Atrial Fibrillation Follow-up Investigation of Rhythm Management (AFFIRM)" and the 'Rate Control versus Electrical Cardioversion for Persistent Atrial Fibrillation (RACE) Study, were among the two landmark trials comparing rate versus rhythm control strategies and their impact on outcomes. ${ }^{9,10}$ The results showed no discernible difference between the two treatment strategies in terms of outcomes. Some of the suggested explanations for the results of the rhythm control strategy were the suboptimal use of anticoagulation, and possible toxicity induced by the used antiarrhythmic agents. However, subgroup analysis of the AFFIRM trial suggested that conversion to sinus rhythm (independently of the treatment strategy) and use of oral anticoagulation were independent predictors of survival. Conversely, antiarrhythmic agents led to complications and increased mortality. ${ }^{9}$

Although, stroke and other embolic complications can be minimized by appropriate use of anticoagulation, conversion to sinus rhythm improves patients symptoms as well as quality of life. ${ }^{11}$ Cardioversion works by depolarization of all cardiac myocytes within the heart, which results in termination of re-entry circuits and allows heart to return to sinus rhythm. ${ }^{12}$

Factors known to affect the success of cardioversion include AF episode duration and left atrial size. ${ }^{13}$ In a study by Kuppahally SS et al. ${ }^{14}$ immediate success rate of direct current cardioversion for $\mathrm{AF}$ was $65.7 \%$ and 1 year success rate was $47 \%$. Atrial fibrillation duration of less than 3 months and pre-cardioversion treatment with antiarrhythmic medications improved immediate success. Independent predictors of recurrence included, patient's age less than 65 years, paroxysmal atrial fibrillation (PAF) as well as alcohol consumption. ${ }^{14}$ Van Gelder et al. reported initial 
success of direct current cardioversion (DCCV) for AF as $70 \%$ and for atrial flutter (AFL) as high as $96 \%$ ( 13).

All these studies were done in the more developed health care setups and there is no data available from developing world health care set-up like our population. We aimed to study the indications of DCCV in a Pakistani population, characteristics of patients, success rate of DCCV and complications associated with it.

\section{METHODOLOGY}

It was a retrospective study conducted after the approval of the hospital ethical review committee. We reviewed the hospital record files of fifty six patients who got admitted for DCCV to the coronary care unit (CCU), between January 2013 and December 2017. Three patients were found to have left atrial appendage thrombus on trans-esophageal echocardiogram and did not undergo DCCV.

For the remaining 53 patients, demographic data including age, gender, as well as indication of cardioversion, duration of arrhythmia and date of DCCV were retrieved from the written medical records. Comorbid conditions and cardiac risk factors were recorded including: diabetes mellitus, hypertension, coronary artery disease, congestive heart failure, cardiomyopathy, valvular heart disease, chronic obstructive pulmonary disease, and hyperthyroidism. Echocardiograms of the patients were reviewed for left atrial (LA) size and left ventricular (LV) ejection fraction.

After obtaining written informed consent, DCCV was performed under deep sedation by using LIFEPAK 20e Defibrillator. Transcutaneous pads or paddles were used and single direction wave shocks were delivered with escalating energy levels (50-360 Joules). Patients who were not on anticoagulation for at least four weeks prior to DCCV or those who were on sub-therapeutic doses, underwent transesophageal echocardiogram (TEE) to rule out left atrial appendage thrombus. The DCCV was deemed successful, if the patients reverted to sinus rhythm immediately after the procedure.

All patients were followed for up to a year after the procedure at myriad intervals by reviewing hospital records and charts including outpatient visits, emergency room visits and readmission, for recurrence of the index arrhythmias or other complications.
After creating a database, we encode the data and identifiers were removed... Statistical Package for Social Sciences (SPSS) version 23 was used for statistical analyses. We expressed the continuous variables as mean value with standard deviations while categorical variables were expressed as frequencies and percentages. Chi-square and Fisher`s exact tests were used for the univariate analysis, in order to analyze the relationship of different variables with the success rate of DCCV. A p-value of $\leq 0.05$ was considered to be statistically significant.

\section{RESULTS}

In our study population, $58.5 \%(\mathrm{n}=31)$ were males with a mean age of the participants of $48.1 \pm 18$ years and mean body mass index (BMI) of $28.3 \pm$ $4.4 \mathrm{~kg} / \mathrm{m}^{2}$. The presenting rhythm was AFL in $56.6 \%$ of the study population (30), while the rest of them had AF. Only 17 patients (32.1\%) had valvular heart disease and 08 patients $(15.1 \%)$ had cardiomyopathy (six of them had ischemic cardiomyopathy). Only $13 \%$ (7) patients had underlying congenital cardiac malformations. Diabetes mellitus was found in 12 (22.6\%), hypertension in $20(37.7 \%)$ and coronary artery disease was present in $10(18.9 \%)$ patients. Table 1 summarizes the comparison of baseline characteristics of patients with atrial fibrillation and atrial flutter.

Table 1: Comparison of baseline characteristics of patients with atrial fibrillation and atrial flutter

\begin{tabular}{|c|c|c|c|}
\hline & $\begin{array}{l}\text { Whole } \\
\text { Cohort }\end{array}$ & $\begin{array}{c}\text { Atrial } \\
\text { Fibrillation }\end{array}$ & $\begin{array}{c}\text { Atrial } \\
\text { Flutter }\end{array}$ \\
\hline Total $(\mathbf{N})$ & $\mathbf{n}=53$ & $\mathrm{n}=\mathbf{2 3}$ & $\mathbf{n}=\mathbf{3 0}$ \\
\hline \multicolumn{4}{|c|}{ Baseline Characteristics } \\
\hline Age (years) & $48.1 \pm 18.4$ & $49.2 \pm 16.9$ & $47.3 \pm 19.7$ \\
\hline Males & $31(58.5 \%)$ & $12(52.2 \%)$ & $19(63.3 \%)$ \\
\hline Females & $22(41.5 \%)$ & $11(47.8 \%)$ & $11(36.7 \%)$ \\
\hline $\begin{array}{l}\text { Body Mass } \\
\text { Index }\left(\mathrm{kg} / \mathrm{m}^{2}\right)\end{array}$ & $28.3 \pm 5$ & $29.8 \pm 6$ & $27 \pm 4$ \\
\hline $\begin{array}{l}\text { Diabetes } \\
\text { Mellitus }\end{array}$ & $12(22.6 \%)$ & $8(34.8 \%)$ & $4(13.3 \%)$ \\
\hline Hypertension & $20(37.7 \%)$ & $10(43.5 \%)$ & $10(33.3 \%)$ \\
\hline $\begin{array}{l}\text { Coronary Artery } \\
\text { Disease }\end{array}$ & $10(18.9 \%)$ & $2(8.7 \%)$ & $8(26.7 \%)$ \\
\hline $\begin{array}{ll}\text { Valvular Hear } \\
\text { Disease }\end{array}$ & $16(30.1 \%)$ & $6(26 \%)$ & $10(33.3 \%)$ \\
\hline $\begin{array}{l}\text { Thyroid } \\
\text { Disorders }\end{array}$ & $3(5.6 \%)$ & $1(4.3 \%)$ & $2(6.7 \%)$ \\
\hline $\begin{array}{l}\text { LA volume } \\
\text { index }\left(\mathrm{ml} / \mathrm{m}^{2}\right)\end{array}$ & $45.3 \pm 14$ & $45.3 \pm 14.3$ & $45.3 \pm 14.5$ \\
\hline $\begin{array}{l}\text { Mean Ejection } \\
\text { Fraction }\end{array}$ & $49.5 \pm 11.6 \%$ & $50.7 \pm 10 \%$ & $48.5 \pm 12 \%$ \\
\hline \multicolumn{4}{|c|}{ Antiarrhythmic Drugs Before Cardioversion } \\
\hline $\begin{array}{l}\text { Amiodarone } \\
\text { with beta } \\
\text { blockers }\end{array}$ & $30(57.6 \%)$ & $17(73.9 \%)$ & $13(43.3 \%)$ \\
\hline
\end{tabular}




\begin{tabular}{|l|c|c|c|}
\hline $\begin{array}{l}\text { Beta blockers } \\
\text { only }\end{array}$ & $19(36.5 \%)$ & $5(21.7 \%)$ & $14(46.7 \%)$ \\
\hline $\begin{array}{l}\text { Amiodarone } \\
\text { with Calcium } \\
\text { channel } \\
\text { blockers }\end{array}$ & $02(3.8 \%)$ & None & $2(6.7 \%)$ \\
\hline $\begin{array}{l}\text { Calcium } \\
\text { channel } \\
\text { blockers only }\end{array}$ & $02(3.8 \%)$ & $1(4.3 \%)$ & $1(3.3 \%)$ \\
\hline
\end{tabular}

Arrhythmia related symptoms (palpitations, fatigue, dizziness and shortness of breath) were the indication of DCCV in 44\% (23) of the subjects, while $38 \%$ (20) were cardioverted due to uncontrolled ventricular rate. Only seventeen percent (9) of the patients underwent cardioversion due to TIC. One patient (2\%) required cardioversion as he was not able to tolerate antiarrhythmic drugs (AAD).

Mean ejection fraction was $49.49 \pm 11.6 \%$ and mean left atrial volume index was $45.3 \pm 14.2 \mathrm{ml} / \mathrm{m}^{2}$. TEE was done in $30.2 \%$ (16) of the patients before the procedure, in order to evaluate for left atrial appendage thrombus.

In our study population, $98.1 \%$ (52) were successfully cardioverted into sinus rhythm with a median energy requirement of 100 joules. Initial success of cardioversion for AFL was $100 \%$ and for $\mathrm{AF}$ was $95.6 \%$. Of all the patients who underwent cardioversion, 98\% (52) patients followed up till 6 months after DCCV, while $92.5 \%$ (49) followed up till 1 year post DCCV (Figure 1A).

Among all the patients who underwent successful cardioversion, $100 \%$ (52) of them were found in sinus rhythm at six weeks follow up, $94.2 \%$ (49) at six months follow up and $73 \%$ (38) remained in sinus rhythm at one year follow up. There was no difference in the recurrence of arrhythmia at 1 year in patients with atrial fibrillation and atrial flutter with an odds ratio for recurrence of arrhythmia 0.873 (95\% CI 0.226-3.367) (Figure 1B).

Out of these 52 patients, $30(57.6 \%)$ were on amiodarone and beta blockers at the time of DCCV and $19(36.5 \%)$ patients were on beta blockers only. All of the patients received anticoagulation for more than four weeks after cardioversion and long term anticoagulation was continued if required as per the CHA2DS2VASc score.

About $74 \%$ (39) of the cases were cardioverted under supervision of the primary cardiologist, who was credentialed for sedation and the anesthesiologist was not called in. Only 2 patients required mechanical ventilation after cardioversion as they were unable to maintain airway due to deep sedation and they got extubated successfully within 24 hours. None of the patients required temporary or permanent pacemaker, no one developed aspiration pneumonia or stroke after cardioversion. There was no death related to cardioversion. Mean hospital stay for our study population was around $1.17 \pm 0.4$ days (Table 2 ).

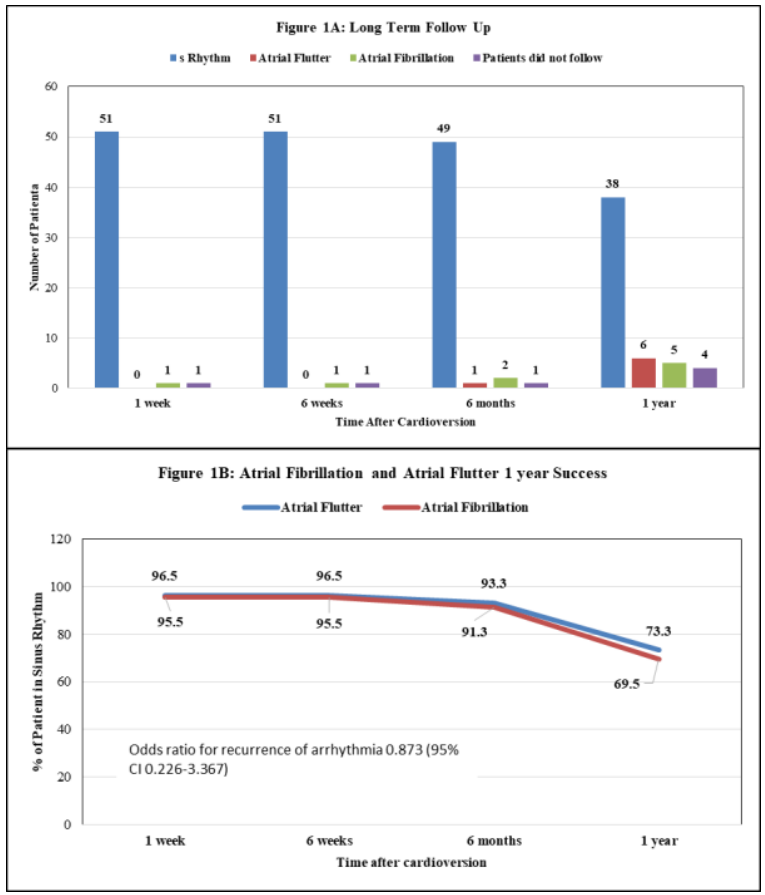

Table 2: Comparison of cardioversion procedure and complications of patients with atrial fibrillation and atrial

\begin{tabular}{|l|c|c|c|}
\hline \multirow{2}{*}{} & $\begin{array}{c}\text { Whole } \\
\text { Cohort }\end{array}$ & $\begin{array}{c}\text { Atrial } \\
\text { Fibrillatio } \\
\mathbf{n}\end{array}$ & $\begin{array}{c}\text { Atrial } \\
\text { Flutter }\end{array}$ \\
\cline { 2 - 4 } & $\mathbf{n = 5 3}$ & $\mathbf{n = 2 3}$ & $\mathbf{n = 3 0}$ \\
\hline Cardioversion Procedure & \multicolumn{2}{|c|}{} \\
\hline $\begin{array}{l}\text { Patients required } \\
\text { Transesophageal } \\
\text { echocardiogram } \\
\text { (TEE) before } \\
\text { cardioversion }\end{array}$ & $16(30.2 \%$ & $7(30.4 \%)$ & $9(30 \%)$ \\
\hline $\begin{array}{l}\text { Mean energy } \\
\text { required (Joules) }\end{array}$ & $115.2 \pm 63.2$ & $148 \pm 78$ & $90 \pm 30$ \\
\hline $\begin{array}{l}\text { Average No of } \\
\text { Shocks of }\end{array}$ & $1.51 \pm 0.67$ & $1.2 \pm 0.7$ & $1.9 \pm 0.7$ \\
\hline $\begin{array}{l}\text { Use } \\
\text { Transcutaneous } \\
\text { Pads }\end{array}$ & $38(71.6 \%)$ & $20(87 \%)$ & $18(60 \%)$ \\
\hline $\begin{array}{l}\text { Anterior/posterio } \\
\text { r position }\end{array}$ & $5(13.1 \%)$ & $4(20 \%)$ & $1(5.5 \%)$ \\
\hline $\begin{array}{l}\text { Anterior/lateral } \\
\text { position }\end{array}$ & $33(86.8 \%)$ & $16(80 \%)$ & $17(94.5 \%)$ \\
\hline Complications & None & None & None \\
\hline $\begin{array}{l}\text { Aspiration } \\
\text { Pneumonia }\end{array}$ & \multicolumn{3}{|l}{} \\
\hline
\end{tabular}




\begin{tabular}{|l|c|c|c|}
\hline Requiring NIMV & $1(1.8 \%)$ & $1(4.3 \%)$ & $0(0 \%)$ \\
\hline $\begin{array}{l}\text { Requiring } \\
\text { Invasive } \\
\text { Mechanical } \\
\text { Ventilation }\end{array}$ & $1(1.8 \%)$ & $1(4.3 \%)$ & $0(0 \%)$ \\
\hline $\begin{array}{l}\text { Stroke related to } \\
\text { Cardioversion }\end{array}$ & None & None & None \\
\hline $\begin{array}{l}\text { Requirement of } \\
\text { Pacing device }\end{array}$ & None & None & None \\
\hline $\begin{array}{l}\text { Death related to } \\
\text { Cardioversion }\end{array}$ & None & None & None \\
\hline $\begin{array}{l}\text { Mean hospital } \\
\text { stay (days) }\end{array}$ & $1.17 \pm 0.4$ & $1.13 \pm 0.3$ & $1.20 \pm 0.4$ \\
\hline
\end{tabular}

On univariate analysis, there was no difference in success rate between males and females $(\mathrm{p}=0.585)$. Patients with age 65 years or above and those below 65 years had similar success rates $(p=0.774)$. None of the pre-existing co-morbid conditions significantly influenced the success of the procedure (Table 3 ).

There was no difference in success rate between $\mathrm{AF}$ and AFL, $95.5 \%$ vs. $100 \%$, respectively $(\mathrm{p}=0.434)$. The patients with a left atrial size/volume less or more than $41 \mathrm{ml} / \mathrm{m} 2$ had no difference in the initial success rate.

Table 3: Factors affecting Success Rate of Electrical Cardioversion

\begin{tabular}{|c|c|c|}
\hline Variables & $\begin{array}{c}\text { P- } \\
\text { value }\end{array}$ & OR $(95 \%$ CI $)$ \\
\hline Age, years $(<65$ vs. $\geq 65)$ & 0.774 & $1.025 \quad(0.977-1.076)$ \\
\hline Gender (male vs. female) & 0.585 & $0.968(0.908-1.032)$ \\
\hline BMI $(<30$ vs. $\geq 30)$ & 0.679 & $0.972(0.920-1.027)$ \\
\hline Diabetes & 0.226 & $0.917(0.773-1.087)$ \\
\hline Hypertension & 0.377 & $0.950(0.859-1.050)$ \\
\hline Coronary artery diseases & 0.811 & $1.024(0.978-1072)$ \\
\hline $\begin{array}{l}\text { Primary arrhythmia (atrial } \\
\text { flutter vs. atrial fibrillation) }\end{array}$ & 0.434 & $1.045(0.958-1.141)$ \\
\hline $\begin{array}{l}\text { LA volume }\left(\mathrm{ml} / \mathrm{m}^{2}\right) \\
(<41 \text { vs. } \geq 41)\end{array}$ & 0.491 & $1.040(0.963-1.123)$ \\
\hline $\begin{array}{l}\text { Maximum energy } \\
\text { Required, Joules } \\
(50-100 \text { vs. }>150) \\
\end{array}$ & 0.887 & $0.979(0.978-1.021)$ \\
\hline $\begin{array}{l}\text { Use of amiodarone before } \\
\text { cardioversion }\end{array}$ & 0.396 & $1.050(0.954-1.154)$ \\
\hline
\end{tabular}

\section{DISCUSSION}

This is the first study from Pakistan, on patients undergoing DCCV for atrial fibrillation and flutter... Overall success of the procedure for both AF and AFL to sinus rhythm was $98 \%$ (95.5\% for atrial fibrillation and $100 \%$ for atrial flutter, respectively), which is higher than the wide range reported in literature. A study by Van Gelder et al. included two-hundred fortysix patients who underwent DCCV with a mean follow up of 260 days. Successful cardioversion was achieved in around $70 \%$ of patients with $\mathrm{AF}$ and in more than
95\% of patients with AFL. ${ }^{13}$ In another study which prospectively followed 1355 consecutive patients, who underwent DCCV in 96 Spanish hospitals, successful cardioversion to sinus rhythm was achieved in $92 \%$ of the patients. ${ }^{15}$ In a retrospective study by Kuppahally, et al. in California, which included 370 patients with AF showed an initial success of $65.7 \% .^{14}$ In literature, a wide range of long term success is reported. In the study by Kuppahally et al. around $72 \%$ of the patients remained in sinus rhythm at the end of 1 year after successful cardioversion. ${ }^{14}$ Lin JM et al. showed recurrence of as high as $47 \%$ within seven months after successful cardioversion. ${ }^{16}$ A metaanalysis by Coplen et al. showed recurrence rate of more than $50 \%$ at 1 year after successful cardioversion. ${ }^{17}$ Frick et al. studied 166 patients prospectively and, reported recurrence of $63 \%$ at 4 weeks after cardioversion. ${ }^{18}$ Overall, our data shows relatively high success rate and lower rate of recurrence, which could possibly be explained by the selection of the patients. Our study population had lower prevalence of valvular heart disease, relatively small left atrial size and majority of them had atrial flutter, that's why we found higher success rate and low recurrence at one year follow up,

In the literature, multiple factors are reported to affect the success of DCCV and arrhythmia recurrence after successful cardioversion. Study by Isabelle et al reported that the duration of arrhythmia $(\mathrm{p}<0.001)$, type of arrhythmia (AF vs. AFL, p<0.02) and age of the patients $(\mathrm{p}<0.05)$ were independently associated with cardioversion success. ${ }^{1}$ In a study by Kuppahally et al. duration of arrhythmia and pretreatment with $\mathrm{AAD}$ were independently associated with procedural success. However, AAD did not reduce arrhythmia recurrence significantly. ${ }^{14}$ Frick et al. reported duration of atrial fibrillation as a major predictor of cardioversion success. ${ }^{18}$ Another study reported arryrhmia duration of less than one year as a predictor of success. ${ }^{19}$ Based on the variable results, it is reasonable to attempt DCCV even in patients with arrhythmia of unknown duration.

The left atrial (LA) size has been reported as a powerful predictor of arrhythmia recurrence after successful cardioversion in the literature. ${ }^{20,21}$ Study by Ditric et al. reported that recurrence is more likely within six months, if patients have left atrial enlargement at the time of cardioversion. ${ }^{22}$

In our study age, gender, body mass index, type of arrhythmia, left atrial size/volume and none of the comorbid conditions were found to influence the cardioversion success rate. These findings could be due to small sample size in our study. 
There are several limitations to our study related to its retrospective, nonrandomized study design. The sample size is relatively small. Another limitation, which is shared by most other studies is the intermittent monitoring of arrhythmia after DCCV, which may underestimate the recurrence. This limitation could be overcome by using loop recorders for continuous long term monitoring but this remains a cost and effort intensive methodology.

\section{CONCLUSION}

In a low to middle income (developing) country, the immediate procedural success of DCCV is high (98\%) and allows more than two thirds of the population to be in normal sinus rhythm at one year. Patient selection and premedication with antiarrhythmic drugs has a major impact on cardioversion success. For a resource limited health care setup, electrical cardioversion may be a good initial strategy to offer to patients for rhythm control.

\section{AUTHORS' CONTRIBUTION}

IA and AHK: Concept and design, data acquisition, interpretation, drafting, final approval, and agree to be accountable for all aspects of the work. HS, BA, and PS: Data acquisition, interpretation, drafting, final approval and agree to be accountable for all aspects of the work.

Conflict of interest: Authors declared no conflict of interest.

\section{REFERENCES}

1. Freedman B, Potpara TS, Lip GY. Stroke prevention in atrial fibrillation. Lancet. 2016;388(10046):806-17.

2. Do Young Kim SH, Ryu KH. Tachycardia induced cardiomyopathy. Kor Cir J. 2019;49(9):808.

3. Ellis ER, Josephson ME. Heart failure and tachycardia-induced cardiomyopathy. Curr Heart Fail Rep. 2013;10(4):296-306.

4. Mueller KA, Heinzmann D, Klingel K, Fallier-Becker P, Kandolf R, Kilias A, et al. Histopathological and immunological characteristics of tachycardia-induced cardiomyopathy. J Am Coll Cardiol. 2017;69(17):2160-72.

5. Ceornodolea AD, BAL R, Severens JL. Epidemiology and management of atrial fibrillation and stroke: review of data from four European countries. Stroke Res Treat. 2017; 2017:8593207.

6. Calkins H, Hindricks G, Cappato R, Kim YH, Saad EB, Aguinaga L, et al. 2017 HRS/EHRA/ECAS/APHRS/SOLAECE expert consensus statement on catheter and surgical ablation of atrial fibrillation: Executive summary. J Arrhythm. 2017;33(5):369409.

7. Blomström-Lundqvist C, Gizurarson S, Schwieler J, Jensen SM, Bergfeldt L, Kennebäck G, et al. Effect of catheter ablation vs antiarrhythmic medication on quality of life in patients with atrial fibrillation: the CAPTAF randomized clinical trial. JAMA 2019;321(11):1059-68.

\section{Address for Correspondence:}

Dr. Aamir Hameed Khan, Professor of Medicine and Consultant Cardiologist, Section of Cardiology, Department of Medicine, Aga Khan University, Stadium road, Karachi, Pakistan.

Email: aamir.hameed@aku.edu
8. January CT, Wann LS, Calkins H, Chen LY, Cigarroa JE, Cleveland JC et al. 2019 AHA/ACC/HRS focused update of the 2014 AHA/ACC/HRS guideline for the management of patients with atrial fibrillation: a report of the American College of Cardiology/American Heart Association Task Force on Clinical Practice Guidelines and the Heart Rhythm Society. JACC. 2019;74(1):104-32

9. AFFIRM Investigators. Relationships between sinus rhythm, treatment, and survival in the Atrial Fibrillation Follow-Up Investigation of Rhythm Management (AFFIRM) Study. Circulation. 2004;109(12):1509-13.

10. Van Gelder IC, Hagens VE, Bosker HA, Kingma JH, Kamp O, Kingma $\mathrm{T}$ et al. A comparison of rate control and rhythm control in patients with recurrent persistent atrial fibrillation. $\mathrm{N}$ Engl $\mathrm{J}$ Med. 2002;347(23):1834-40.

11. Mead GE, Elder A, Flapan AD, Cordina J. Electrical cardioversion for atrial fibrillation and flutter. Cochrane Database Syst Rev. 2002;(1):CD002903.

12. V Lown B. New method for terminating cardiac arrythmias. Use of synchronized capacitor discharge. JAMA. 1962; 182:548-55.

13. Van Gelder IC, Crijns HJ, Van Gilst WH, Verwer R, Lie KI. Prediction of uneventful cardioversion and maintenance of sinus rhythm from direct-current electrical cardioversion of chronic atrial fibrillation and flutter. Am J Cardio. 1991;68(1):41-6.

14. Kuppahally SS, Foster E, Shoor S, Steimle AE. Short-term and long-term success of electrical cardioversion in atrial fibrillation in managed care system. Int Arc Med. 2009;2(1):39.

15. Alegret JM, Vinolas X, Sagristá J, Hernandez-Madrid A, Pérez L, Sabaté $\mathrm{X}$ et al. Predictors of success and effect of biphasic energy on electrical cardioversion in patients with persistent atrial fibrillation. Europace. 2007;9(10):942-6.

16. Lin JM, Lin JL, Lai LP, Tseng YZ, Huang SK. Predictors of clinical recurrence after successful electrical cardioversion of chronic persistent atrial fibrillation: clinical and electrophysiological observations. Cardiology. 2002;97(3):133-7.

17. Coplen SE, Antman EM, Berlin JA, Hewitt P, Chalmers TC. Efficacy and safety of quinidine therapy for maintenance of sinus rhythm after cardioversion. A meta-analysis of randomized control trials. Circulation. 1990;82(4):1106-16.

18. Frick M, Frykman V, Jensen-Urstad M, Östergren J. Factors predicting success rate and recurrence of atrial fibrillation after first electrical cardioversion in patients with persistent atrial fibrillation. Clin Cardiol. 2001;24(3):238-44.

19. Boriani G, Diemberger I, Biffi M, Domenichini G, Martignani C, Valzania $\mathrm{C}$ et al. Electrical cardioversion for persistent atrial fibrillation or atrial flutter in clinical practice: predictors of longterm outcome. Int J Clin Prac. 2007;61(5):748-56.

20. Raitt MH, Volgman AS, Zoble RG, Charbonneau L, Padder FA, O'Hara GE et al. AFFIRM Investigators. Prediction of the recurrence of atrial fibrillation after cardioversion in the Atrial Fibrillation Follow-up Investigation of Rhythm Management (AFFIRM) study. Am Heart J. 2006;151(2):390-6.

21. Olshansky B, Heller EN, Mitchell LB, Chandler M, Slater W, Green $\mathrm{M}$ at al. AFFIRM Investigators. Are transthoracic echocardiographic parameters associated with atrial fibrillation recurrence or stroke? Results from the atrial fibrillation follow-up investigation of rhythm management (AFFIRM) study. JACC. 2005;45(12):2026-33.

22. Dittrich HC, Erickson JS, Schneiderman T, Blacky AR, Savides T, Nicod PH. Echocardiographic and clinical predictors for outcome of elective cardioversion of atrial fibrillation. Am J Cardiol. 1989;63(3):193-7. 